\title{
Optic nerve enlargement and leukodystrophy \\ An unusual finding of the infantile form of Krabbe disease
}

\author{
Antonio Milton Lima Garcia', Norma Martins Menezes Morais', \\ Lygia Ohlweiler', Maria Isabel Bragatti Winckler', Josiane Ranzan', \\ Osvaldo Alfonso Pinto Artigalás², Luise Lapagesse de Camargo Pinto², \\ Cristina Brinckmann Oliveira Netto ${ }^{3}$, Patrícia Ashton-Prolla ${ }^{4}$, \\ Leonardo Vedolin ${ }^{5}$, Rudimar dos Santos Riesgo ${ }^{6}$, Newra Tellechea Rotta ${ }^{7}$
}

Leukodystrophies are a heterogeneous group of inherited neurological disorders characterized by progressive demyelination that causes loss of motor, sensory and intellectual functions leading to a fatal outcome. These disorders result from dysfunctions in myelin metabolism as a consequence of genetic enzymatic defects specific to each leukodystrophy subtype ${ }^{1}$. Krabbe disease (KD), also called globoid cell leukodystrophy (GCL), is inherited in an autosomal recessive pattern and has an estimated incidence of 1 in each 100,000/200,000 live births. It affects the peripheral and central nervous system $(\mathrm{CNS})^{2}$.

We report on two cases of the infantile form of KD and describe MRI findings that suggest optic nerve enlargement (ONE).

\section{CASES}

\section{Case 1}

A 6-month-old white female patient was hospitalized due to respiratory infection symptoms. Her neuropsychological and motor development had been normal up to 3 months of age when she had bronchiolitis followed by progressive loss of developmental landmarks and slow progression of spasticity, but no seizures. The patient had a brother with a similar neuro- logical condition that died at 6 months of age due to intestinal obstruction. Neurological examinations revealed generalized hypertonicity of the 4 limbs and decreased muscle mass, irritability and inconsolable crying, increased phasic-type myotatic reflexes and bilateral extensor plantar reflex. Cerebrospinal fluid was normal. Electroencephalogram showed signs of severe diffuse encephalopathy. Brain CT findings were suggestive of diffuse cerebral atrophy. MRI changes are described in Fig 1. Serum concentration of galactocerebrosidase was much lower than normal. The patient died due to respiratory complications.

\section{Case 2}

A 9-month-old white male patient presented with progressive loss of developmental landmarks, irritability, persistent crying, generalized hypertonicity and opisthotonos at seven months of age. The patient had dysphagia and fever, but no seizures. Perinatal and family histories were not relevant. Neurological examination showed excessive irritability, hypertonicity of the four limbs, hyperreflexia, bilateral extensor plantar reflex and normal fundoscopy findings. CSF showed discrete mononuclear pleocytosis and increase in

\section{Correspondence}

Antonio Milton Lima Garcia Rua Dr Raul Lafayette 80 / 50 51021-220 Recife PE - Brasil

E-mail: amlgarcia@uol.com.br

Received 6 September 2009

Received in final form 14 October 2009 Accepted 26 October 2009

\section{ESPESSAMENTO DE VIAS ÓPTICAS E LEUCODISTROFIA: UM ACHADO POUCO FREOÜENTE DA FORMA INFANTIL DA DOENÇA DE KRABBE}

'Pediatric Neurology Unit, Hospital de Clínicas de Porto Alegre (HCPA), Porto Alegre RS, Brazil; ${ }^{2}$ Genetic Department, HCPA; ${ }^{3}$ Medical Genetic Service, HCPA; ${ }^{4}$ Professor of the Genetic Department, HCPA; ${ }^{5}$ Neuroradiology Department of Hospital Moinhos de Vento, Porto Alegre RS, Brazil; ${ }^{6}$ Pediatric Neurologist, Head of the Pediatric Neurology Unit, HCPA. Adjunct Professor, Universidade Federal do Rio Grande do Sul, Porto Alegre RS, Brazil; ${ }^{7}$ Pediatric Neurologist, Adjunct Professor, Universidade Federal do Rio Grande do Sul, Porto Alegre RS, Brazil. 


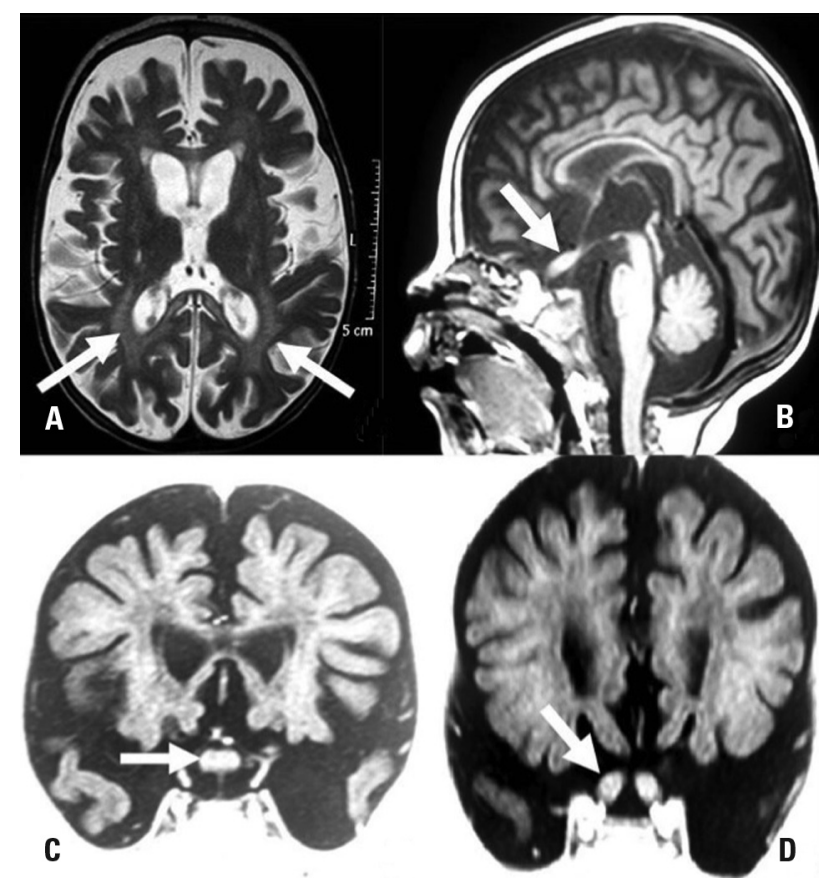

Fig 1. Krabbe disease. T1- and T2-weighted and FLAIR images show important reduction of brain volume, diffuse reduction of thickness of periventricular white matter marked by hyperintensity of periventricular signal in $\mathrm{T} 2$ sequences [A]. Chiasm [C] and optic nerve [B and D] enlargement are also seen.

total protein content. Brain CT scan showed bilateral symmetrical hyperdensities located in the thalami, corona radiata and caudate nucleus. MRI findings are described in Fig 2. Serum B-galactocerebrosidase was not detected.

In both cases, the parents signed an informed consent for this publication.

\section{DISCUSSION}

$\mathrm{KD}$ is associated with a defective gene in the 14q31 chromosome, which leads to a reduction in the production of galactosylceramidase, a lysosomal enzyme responsible for the hydrolysis of galactosylceramide into ceramide and galactose ${ }^{3,4}$. Consequently, galactocerebrosidase, as well as galactosylsphingosine, which causes cerebral toxicity, accumulate in macrophages ${ }^{2}$. Their intracytoplasmic accumulation in macrophages and CSF cells leads to the formation of globoid cells, degeneration of oligodendrocytes, and, consequently, myelin deficiency and demyelination of white matter ${ }^{5}$.

The onset of the infantile form of the disease, the most common subtype, occurs at about 6 months of age. Infants usually present with neurodegenerative symptoms that progress to spastic quadriparesis, tonic spasms, extreme irritability, inconsolable crying, secondary blindness, progressive optic atrophy, and death usually due to severe respiratory infection at about the second year of life. The juvenile and adult forms are characterized by in-

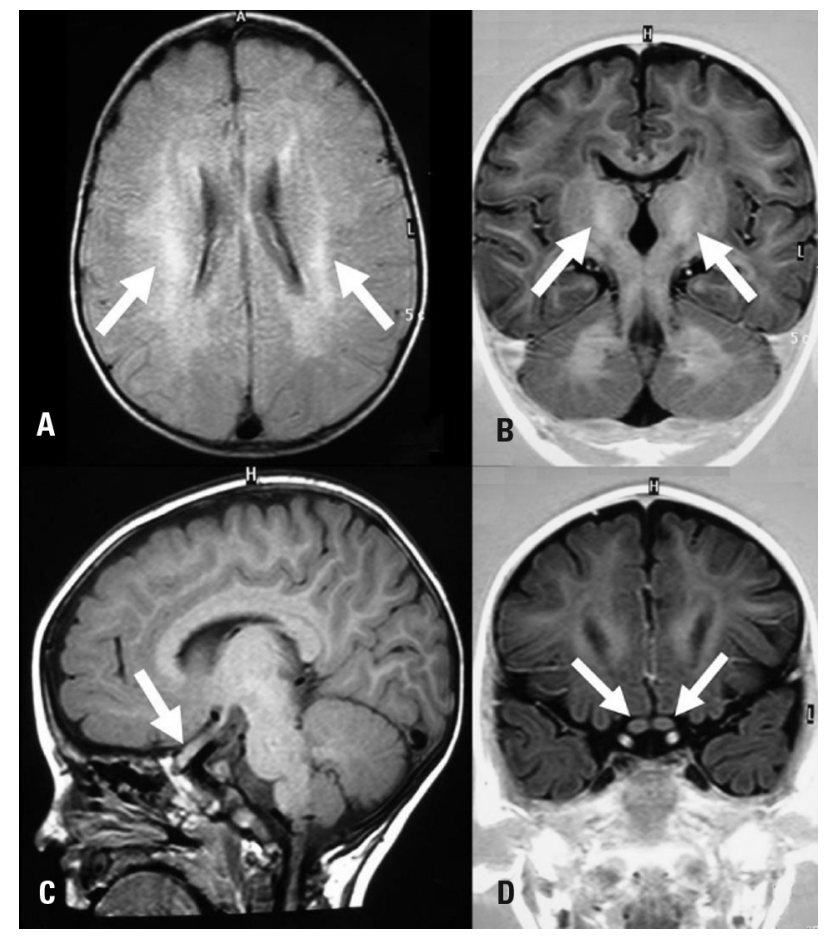

Fig 2. Krabbe disease. T1- and T2-weighted and FLAIR images show hyperintense periventricular $[A]$ and thalamus $[B]$ signal bilaterally. Optic nerve enlargement [C and D] is also seen.

sidious visual compromise, cognitive deterioration and gait disorders ${ }^{6-8}$.

Brain CT scans in KD show characteristic hyperdensities in the thalami, the corona radiata, the body of the caudate nucleus, the cerebellum and the brainstem ${ }^{3,9}$. Calcifications or globoid cell grouping may hypothetically explain the appearance of such images, but the real pathogenesis keep unexplained ${ }^{10}$.

MRI shows signal abnormalities of similar distribution. Hypointense signs in T2-weighted images and hyperintense signs in T1-weighted images are seen in the early stages of the disease, but they later progress into hyperintense lesions on T2-weighted images, which suggest defective myelination and demyelization ${ }^{9}$. In the cerebellum, the dentate nucleus and the white matter are typically affected. Clear cerebral and cerebellar atrophy can be seen in the late stages of the disease ${ }^{11}$.

Recent case reports described MRI scans of the spinal cord of patients with KD and found, after contrast injection, diffuse enhancement at the nerve roots of the lumbar spine and low thoracic spine, which suggests the compromise of CNS at this level ${ }^{3,12}$.

Histological findings reported in pioneering studies conducted in the last century showed optic nerve enlargement (ONE) in KD, particularly in its initial phase ${ }^{1,13,14}$. ONE, which was found in the brain MRI scans of our two patients, was also described in recent studies that stressed 
the importance of these radiological findings ${ }^{1-3,15}$. Hittmair et al. reported on the association of this finding with hypertrophy of other intracranial nerves ${ }^{15}$.

The following disorders should be included in the differential diagnosis of KD: optic nerve glioma with dural ectasia, frequently in type 1 neurofibromatosis; nerve sheath meningioma; granulomatous or histiocytic infiltration of optic nerves, leukemia, orbit pseudotumor, juvenile xanthogranuloma, post viral optic neuritis; optic nerve medulloepithelioma; and retinoblastoma with optic nerve compromise?

Spectroscopic findings in KD may include a low Nacetylaspartate (NAA) concentration, choline peaks (Cho), and an abnormally high Cho:NAA ratio in white matter. This reflects the presence of diffuse axonal degeneration and the proliferation of glial cells ${ }^{2}$. Marked increases in the inositol (Ins)-to-NAA ratio is a sign of elevated astrocytosis in cerebral white matter ${ }^{6}$.

Evaluation of the degree of anisotropy in the white matter of patients with KD using a new imaging method, diffusion tensor MR imaging (DTI), suggests that this method may detect changes in white matter earlier than MRI ${ }^{16,17}$.

The diagnosis of KD is challenging because of the large number of demyelinating diseases and leukodystrophies, as well as the similarities between their clinical and imaging findings. Specific neuroimaging findings may help to establish this diagnosis. The detection of ONE on MRI scans, not found in other types of leukodystrophies, is an auxiliary tool in the differential diagnosis of KD.

In a pacient with the clinical features of a metabolic disease, KD should be the main diagnostic hypothesis whenever there is evidence of ONE, particularly when associated with their typical intracranial neuroimaging findings.

\section{REFERENCES}

1. Harcourt B, Ashton N. Ultrastructure of the optic nerve in Krabbe's leucodystrophy. Brit J Ophthalmol 1973;57:885-891.

2. Veena AN, Meher AU, Pradeep K, Bhavin GJ. Krabbe disease: unusual MRI findings. Pediatr Radiol 2006;36:61-64.

3. Vasconcellos E, Smith M. MRI nerve root enhancement in Krabbe disease. Pediatr Neurol 1998;19:151-152.

4. Zlotogora B, Chakraborty S, Knowlton R G, et al. Krabbe's disease locus mapped to chromossome 14 by genetic linkage. Am J Hum Genet 1990; 47:37-44.

5. Kwan E, Drace J, Enzmann D. Specific CT findings in Krabbe's disease. AJNR 1984;5:453-458.

6. Brockmann K, Dechent P, Wilken B, Rush O, Frahm J, Hanefeld F. Proton MRS profile of cerebral metabolic abnormalities in Krabbe disease. Neurology 2003;60:819-825.

7. Crome L, Hanefel F, Patrick D, Wilson J. Late onset globoid cell leucodistrophy. Brain 1973;96:841-848.

8. Thomas P K, Halpern J P, King R H, Patrick D. Galactosylceramide lipidosis: novel presentation as a slowly progressive spinocerebellar degeneration. Ann Neurol 1984;16:618-620.

9. Jones BV, Barron TF, Towfighi J. Optic nerve enlargement in Krabbe's Disease. Am J Neuroradiol 1999;20:1228-1231.

10. Feanny S J, Chuang S H, Becker L E, et al Intracerebral paraventricular hyperdensities: a new CT sign in Krabbe globoid cell leukodystrophy. J Inherit Metab Dis, 1987;10:24-27.

11. Barkovich J A. Pedriatric neuroimaging. $3^{\text {rd }}$ Ed. Philadelphia: Lippincott Williams \& Wilkins, 2000.

12. Curtis A, Cesar C S, David DD. Intracranial and spine MR imaging findings associated with Krabbe's disease: case report. AJNR Am J Neuroradiol 2001;22:1782-1785.

13. Krabbe K. A new familial, infantile from of diffuse brain-sclerosis. Brain 1916; 39:73-114.

14. leshima A, Eda I, Matsui A, et al. Computed tomography in Krabbe's disease: comparison with neuropathology. Neuroradiology 1983;25:323-327.

15. Hittmair K, Wimberger D, Wiesbauer P, et al. Early infantile form of Krabbe disease with optic hypertrophy: serial MR examinations and autopsy correlation. AJNR 1994;15:1454-1458.

16. Guo A C, Petrella J R, Kurtzberg J, Provenzale J M. Evaluation of white mater anisotropy in Krabbe disease with diffusion tensor MR imaging: inicial experience. Radiology 2001;218:809-815.

17. Provenzale JM, Escolar M, Kurtzberg J. Quantitative analysis of diffusion tensor imaging data in serial assessment of Krabbe disease. Ann New York Acad Sci 2005;1064:220-229. 